\title{
Cardiac Resynchronization in Mild Heart Failure: All Issues Resolved?
}

\author{
Editorial to "Cardiac Resynchronization Therapy in Patients with Mild Heart Failure: \\ A Systematic Review and Meta-Analysis of Randomized Controlled Trials" by Ronghui \\ Tu et al.
}

\author{
Alexander H. Maass \\ Published online: 19 July 2011 \\ (C) The Author(s) 2011. This article is published with open access at Springerlink.com
}

Cardiac resynchronization therapy (CRT) can improve heart failure symptoms and reduce mortality in advanced heart failure. Implantation rates have been shown to increase steadily in Europe [1, 2] and it is expected they will increase further after the recent updated European guidelines on device therapy in heart failure [3]. What is the evidence for CRT in patients with depressed systolic function but little heart failure symptoms? Until recently there were several studies that demonstrated improvement in symptoms, reduction of heart failure hospitalizations but no significant effect on mortality. The RAFT study was the first randomized study demonstrating a reduction of mortality in patients with NYHA functional class I or II [4]. In this issue of Cardiovascular Drugs and Therapy, Tu et al. present a meta analysis of all trials including patients in this functional class [5]. These include trials that were designed to include mild heart failure patients but also trials where only part of the patients were in better functional classes. This meta-analysis shows that CRT in these patients reduces mortality and leads to reverse remodeling, and reduces hospitalizations or worsening heart failure at the cost of a somewhat higher rate of complications.

Can we now close the books on CRT in mild heart failure? Patient selection remains a critical issue. Subanalyses of the 2 biggest trials, MADIT-CRT and RAFT showed that only patients with QRS durations of $>150 \mathrm{~ms}$ benefit from CRT $[4,6]$. In addition to QRS duration, QRS morphology seems to be important to identify patients most likely to

A. H. Maass $(\bowtie)$

Department of Cardiology, Thoraxcenter,

University Medical Center Groningen, University of Groningen,

P.O. Box 30.001, 9700 RB Groningen, The Netherlands

e-mail: a.h.maass@umcg.nl respond to CRT with classical left bundle branch block being more likely than aspecific intraventricular conduction delay or right bundle branch block. To define specific and sensitive criteria identifying possible responders to CRT is the next critical issue as using the current criteria only $50-70 \%$ of patients show reverse remodeling of the left ventricle. Reverse remodeling, however, is the prerequisite for reduction of hard endpoints such as heart failure hospitalization and mortality [7]. In addition to QRS duration and morphology, there are other known predictors of response, such as etiology of heart failure with better response in nonischemic cardiomyopathy. Echocardiographic dyssynchrony indexes have some predictive value but have failed to be used in daily clinical practice, mostly due to low specificity and high interobserver variability [8]. In addition to finding new parameters to predict response, we might have to move away from classical parameters. It has been recently shown that in patients with an left ventricular ejection fraction (LVEF) of above $35 \%$ the rate of response is comparable to patients with low LVEF [9]. The effects of CRT could even be beneficial in a subgroup of patients with diastolic heart failure since systolic as well as diastolic dyssynchrony can contribute to the pathophysiology of this disorder [10].

Instead of only focusing on patient selection, optimal delivery of CRT is of critical importance [11]. There is an ongoing discussion on the importance of lead position. Even though there is abundant contradicting literature from subanalyses of the landmark trials as well as other retrospective databases, we will have to wait for the results of ongoing randomized trials. First promising results of the TARGET study comparing echocardiography guided lead positioning have been presented at the meeting of the American College of Cardiology this year [12]. The debate is also ongoing about the importance of device programming. 
A recent large prospective study has doubted the importance of $\mathrm{AV}$ delay optimization even though the magnitude of reverse remodeling seemed higher in patients undergoing optimization [13]. Optimal VV delay is less likely to significantly contribute to CRT response, especially in patients with optimal left ventricular lead positions. An overlooked parameter that can influence response to CRT and is also important to improve exercise capacity is the heart rate [14]. Chronotropic incompetence is an important pathophysiological mechanism in heart failure due to desensitization of beta-adrenergic signaling as well as due to drug treatment such as beta-blockers and/or amiodarone. Utilizing the rate sensor of the CRT device can overcome this problem and new physiological rate sensors will be incorporated in the next generation of devices leading to a further improvement of this issue. CRT optimization at higher heart rates is an exciting area of research as most patients are only symptomatic during exercise. There is some literature available but we need more prospective studies to prove that it is worthwhile during these cumbersome optimizations [15].

CRT follow-up is also a chance to optimize pharmacological and physical therapy. Doses of heart failure medication in real life often do not reflect those given in randomized clinical trials. There are multiple reasons for this, including orthostatic symptoms due to hypotension and bradycardia due to beta-blocker treatment. After CRT implantation bradycardia is not an issue any more and reverse remodeling often also improves hypotension and congestion. Follow-up after CRT should routinely include optimization of drug treatment such as trials of reducing diuretics and increasing doses of ACE inhibitors and beta-blockers [16]. Cardiac rehabilitation programs with structured exercise training can also be used after CRT and has been shown to improve exercise capacity and quality of life [17].

Lastly, the occurrence of arrhythmias is important for CRT response. Part of the reduced mortality can be explained by a reduction in life-threatening arrhythmias. In fact it has been shown that response to CRT dramatically reduces the occurrence of ICD therapies [18]. If CRT can also induce reverse remodeling in the atria and reduce the occurrence of atrial fibrillation (AF) remains controversial. Atrial remodeling is more severe than ventricular remodeling and might not be reversible once it has progressed too far [19]. New-onset AF on the other hand is associated with nonresponse and worse outcome in CRT patients [20, 21] probably related to loss of biventricular stimulation. It seems thus important to aggressively treat $\mathrm{AF}$ with a rhythm control strategy and the effecT study (NCT00811382) is currently investigating prospectively if aggressive treatment of AF episodes detected via remote monitoring will improve outcome of these patients.
In conclusion, proving that CRT is efficacious in mildly symptomatic heart failure patients will create more questions than it answers. Extending the indication for CRT will make patient selection, optimization of CRT delivery and programming as well as improvement of drug therapy and treatment of atrial fibrillation even more important. Cardiac resynchronization therapy will more and more become a team effort between specialists in heart failure, echocardiography, and electrophysiology with special interest in device therapy.

Conflicts of Interest A.H.M. has received lecture fees from Medtronic, Biotronik, Boston Scientific, and Sorin.

Open Access This article is distributed under the terms of the Creative Commons Attribution Noncommercial License which permits any noncommercial use, distribution, and reproduction in any medium, provided the original author(s) and source are credited.

\section{References}

1. van Veldhuisen DJ, Maass AH, Priori SG, Stolt P, van Gelder IC, Dickstein K, et al. Implementation of device therapy (cardiac resynchronization therapy and implantable cardioverter defibrillator) for patients with heart failure in Europe: changes from 2004 to 2008. Eur J Heart Fail. 2009;11:114351.

2. Dickstein K, Bogale N, Priori S, Auricchio A, Cleland JG, Gitt A, et al. The European cardiac resynchronization therapy survey. Eur Heart J. 2009;30:2450-60.

3. Dickstein K, Vardas PE, Auricchio A, Daubert JC, Linde C, McMurray J, et al. 2010 focused update of ESC guidelines on device therapy in heart failure: an update of the 2008 ESC guidelines for the diagnosis and treatment of acute and chronic heart failure and the 2007 ESC guidelines for cardiac and resynchronization therapy* Developed with the special contribution of the Heart Failure Association and the European Heart Rhythm Association. Eur J Heart Fail. 2010;12:1143-53.

4. Tang AS, Wells GA, Talajic M, Arnold MO, Sheldon R, Connolly S, et al. Cardiac-resynchronization therapy for mildto-moderate heart failure. New Engl J Med. 2010;363:238595.

5. Tu R, Zhong G, Zeng Z, Wu W, Wu H, Cao X, et al. Cardiac resynchronization therapy in patients with mild heart failure: a systematic review and meta-analysis of randomized controlled trials. Cardiovasc Drugs Ther. 2011;25: this issue.

6. Moss AJ, Hall WJ, Cannom DS, Klein H, Brown MW, Daubert JP, et al. Cardiac-resynchronization therapy for the prevention of heart-failure events. New Engl J Med. 2009;361:1329-38.

7. Foley PW, Chalil S, Khadjooi K, Irwin N, Smith RE, Leyva F. Left ventricular reverse remodelling, long-term clinical outcome, and mode of death after cardiac resynchronization therapy. Eur J Heart Fail. 2011;13:43-51

8. Chung ES, Leon AR, Tavazzi L, Sun JP, Nihoyannopoulos P, Merlino J, et al. Results of the predictors of response to CRT (PROSPECT) trial. Circulation. 2008;117:2608-16.

9. Chung ES, Katra RP, Ghio S, Bax J, Gerritse B, Hilpisch K, et al. Cardiac resynchronization therapy may benefit patients with left 
ventricular ejection fraction $>35 \%$ : a PROSPECT trial substudy. Eur J Heart Fail. 2010;12:581-7.

10. Maass AH, van Veldhuisen DJ. Device therapy in patients with heart failure and preserved ejection fraction (HFPEF): a new frontier? Eur J Heart Fail. 2010;12:527-9.

11. Buck S, Maass AH, van Veldhuisen DJ, Van Gelder IC. Cardiac resynchronisation therapy and the role of optimal device utilisation. Neth Heart J. 2009;17:354-7.

12. Khan FZ, Virdee MS, Begley D, Pugh PJ, Read PA, Fynn SP, et al. Targeted left ventricular lead placement using speckle tracking echocardiography improves the acute hemodynamic response to cardiac resynchronization therapy: a randomized controlled trial. J Am Coll Cardiol. 2011;57:E2033.

13. Ellenbogen KA, Gold MR, Meyer TE, Fernndez Lozano I, Mittal $\mathrm{S}$, Waggoner $\mathrm{AD}$, et al. Primary results from the smartdelay determined $\mathrm{AV}$ optimization: a comparison to other $\mathrm{AV}$ delay methods used in cardiac resynchronization therapy (SMART-AV) trial: a randomized trial comparing empirical, echocardiographyguided, and algorithmic atrioventricular delay programming in cardiac resynchronization therapy. Circulation. 2010;122:2660-8.

14. Maass AH, Buck S, Nieuwland W, Brugemann J, van Veldhuisen DJ, Van Gelder IC. Importance of heart rate during exercise for response to cardiac resynchronization therapy. J Cardiovasc Electrophysiol. 2009;20:773-80.

15. Bogaard MD, Kirkels JH, Hauer RN, Loh P, Doevendans PA, Meine M. Should we optimize cardiac resynchronization therapy during exercise? J Cardiovasc Electrophysiol. 2010;21:1307-16.
16. Remme WJ. Which beta-blocker is most effective in heart failure? Cardiovasc Drugs Ther. 2010;24:351-8.

17. Patwala AY, Woods PR, Sharp L, Goldspink DF, Tan LB, Wright DJ. Maximizing patient benefit from cardiac resynchronization therapy with the addition of structured exercise training: a randomized controlled study. J Am Coll Cardiol. 2009;53:2332-9.

18. Schaer BA, Osswald S, Di Valentino M, Soliman OI, Sticherling $\mathrm{C}$, ten Cate FJ, et al. Close connection between improvement in left ventricular function by cardiac resynchronization therapy and the incidence of arrhythmias in cardiac resynchronization therapy-defibrillator patients. Eur J Heart Fail. 2010;12:132532.

19. De Jong AM, Maass AH, Oberdorf-Maass SU, Van Veldhuisen DJ, Van Gilst WH, Van Gelder IC. Mechanisms of atrial structural changes caused by stretch occurring before and during early atrial fibrillation. Cardiovasc Res. 2011;89:75465.

20. Buck S, Rienstra M, Maass AH, Nieuwland W, Van Veldhuisen DJ, Van Gelder IC. Cardiac resynchronization therapy in patients with heart failure and atrial fibrillation: importance of new-onset atrial fibrillation and total atrial conduction time. Europace. 2008;10:558-65.

21. Smit MD, Maass AH, Hillege HL, Wiesfeld AC, Van Veldhuisen DJ, Van Gelder IC. Prognostic importance of natriuretic peptides and atrial fibrillation in patients receiving cardiac resynchronization therapy. Eur J Heart Fail. 2011;13:543-50. 